\title{
SIR DAVID BRUCE LECTURE 1993 The Primary Care Team
}

16 November 1993, Royal Army Medical College, Millbank, London

\author{
Dr J C Hasler \\ OBE, MD, FRCGP, DA, DCH \\ General Practitioner \\ Sonning Common Health Centre
}

Regional Postgraduate Adviser and Clinical Lecturer in General Practice, University of Oxford Medical School Civilian Consultant in General Practice, Royal Air Force

\section{Introduction}

It is a great honour to be asked to give this year's David Bruce lecture and to have the opportunity of meeting so many friends - friends I have come to know during the time I have been involved with the Defence Medical Services. It was exactly 15 years ago this Sunday that I first made the acquaintance of doctors working in the Armed Forces and it was in this building John Lawson, Alastair Donald, and myself had arrived to spend the night before flying out the next day to conduct the second Joint Committee visit to Germany. I recall that we dined with General Reay, the Commandant at Millbank at the time. I also recall meeting a number of others who were to feature in my subsequent life including Ken Young, the first Director of Army General Practice, and Harvey Mason who was then Command Adviser in General Practice in BAOR. There was also Mark Conroy who, on the day we met him told us he was simultaneously a trainee, trainer and Course Organiser.

You will, I think, understand my confusion with some aspects of the Services which it has taken some years to unravel.

\section{David Bruce}

As many of you know, David Bruce was born in Melbourne in $\mathbf{1 8 5 5}$ where his father, a Scots engineer, was working at the time. After returning home, he went into business in Manchester but later entered Edinburgh University from where he qualified in Medicine in 1881. He joined a general practice in Reigate in Surrey where he met and married Mary Steele, the daughter of a previous doctor in the practice. You may think that things are difficult for young GPs today but David Bruce found himself unable to keep his wife in the style to which she was accustomed and decided the Army Medical Service would provide the appropriate solution. Whether that is still the reason for young doctors entering the Services now I cannot say.

Bruce's contribution to the Army Medical Services and to medicine in general was in the field of infectious disease - the big challenge of the time. He was recognised for his works on cholera, malaria, dysentery, tetanus and a host of other serious problems. It is difficult now, with our understanding of many of the common infections, with immunisation and with modern antibiotics, to comprehend how much of a threat these diseases were and how much time the medical profession had to devote to their management and eradication.

Today our main challenge in medicine is of a quite different nature.

Less dramatic but no less important, the effective management of long term health problems and chronic disease has replaced infectious disease as one of our main preoccupations, both in primary care and secondary care. I like to think that Bruce, were he alive today, might have directed his obvious talents to this field of activity.

\section{Chronic Disease}

In this lecture I want to look first at the size of the problem and a widening appreciation of some of the $\vec{c}$ aetiology. Then I want to examine some of the challenges that face us. Third, I hope to draw out some of the generab principles of effective management. Finally, just in case some of you might wonder whether long term problems is a high priority for you, I want to examine the implications, as I see them, for the Defence Medicaf Services. Given the audience and my own background shall obviously concentrate on the implications for primary medical care.

\begin{tabular}{lc}
\hline Condition & $\begin{array}{c}\text { Number of Consultations } \\
\text { per 2000 Population }\end{array}$ \\
Angina & 37 \\
Hypertension & 261 \\
Epilepsy & 18 \\
Asthma & 97 \\
Diabetes & 52 \\
Anxiety disorder & 112 \\
Depressive disorders & 144 \\
Osteoarthritis & 106 \\
Rheumatoid arthritis & 35 \\
\hline
\end{tabular}

Fig 1. Chronic Disease - Consultations.

\section{The Size of the Problem}

Figure 1 shows the number of consultations, some for some common chronic diseases for a population of 2000 in a UK practice.

Figure 2 shows the numbers of patients with certain problems past and present for my own practice in South Oxfordshire with a population of just over 7000 .

Figure 3 shows the national data from the Chief Medical Officer's report for England for 1991 with the 
Number of Patients

$\begin{array}{lr}\text { Angina } & 189 \\ \text { Hypertension } & 452 \\ \text { Epilepsy } & 55 \\ \text { Asthma } & 771 \\ \text { Diabetes } & 123 \\ \text { Osteoarthritis } & 411 \\ \text { Rheumatoid arthritis } & 43 \\ \text { Gout } & 106 \\ \text { Hormone replacement therapy } & 336 \\ \text { Hypothyroidism } & 72\end{array}$

Fig 2. Sonning Common Health Centre (7200 patients).

\begin{tabular}{lllll} 
& \multicolumn{2}{c}{$\mathbf{1 6 - 4 4}$} & \multicolumn{2}{c}{$\mathbf{4 5 - 6 4}$} \\
& Men & Women & Men & Women \\
\hline $\begin{array}{l}\text { Long standing illness } \\
\begin{array}{l}\text { Limiting long standing } \\
\text { illness }\end{array}\end{array}$ & $23 \%$ & $23 \%$ & $42 \%$ & $41 \%$ \\
\hline
\end{tabular}

CMO Report

\section{Fig. 3. Health Data for England 1991.}

percentages of people reporting some form of ongoing medical problem.

Figure 4 shows some figures for one of the RAF practices in the UK, which may, in fact, be an underestimate. Whilst, clearly the prevalence of diseases like hypertension and diabetes is much lower than in civilian practices, the diseases are not absent which in many ways presents a greater challenge. Because they are dealing with the problems less frequently, Service GPs may have more difficulty in remembering exactly what has to be done at each review. For asthma, and psychoneuroses, on the other hand, Service doctors face exactly the same kind of problem as do civilian doctors. Much asthma is in children and young adults and there is evidence that the incidence of psychoneuroses is increased by some of the inevitable turbulence that Service families have to face.

\section{Number of patients}

$\begin{array}{lr}\text { Asthma } & 65 \\ \text { Diabetes } & 6 \\ \text { Hypertension } & 15 \\ \text { Psychoneurosis } & 37\end{array}$

Fig 4. RAF UK Practice 1993 (2280 patients).

But the figures on numbers of patients do not represent the full story of the distribution and effect of some of these diseases. In a recent study from Limburg in the Netherlands (1) for example, into recurrent medical problems or ones continuing for over six months, the researchers found the distribution skewed, as one would appreciate. Three quarters of the problems were in under a third of the households and nearly half the patients we in $15 \%$ of the household. They also identified the number of other people who were affected by chronic or recurrem problem in one or more members of the household. Thire percent of the population had a long term problem but? further $26 \%$ of the population were involved in some waff. either as parents, partners or children. Whilst as gener駡 practitioners, we recognise the effect of, say asthma, of the rest of the family, we sometimes forget just how marg people are affected.

\begin{tabular}{|c|c|}
\hline \multicolumn{2}{|c|}{ Average annual incidence } \\
\hline $18.7 / 100,000$ & most deprived area \\
\hline $7 / 100,000$ & least deprived area \\
\hline
\end{tabular}

Fig 5. Insulin Dependent Diabetes in Children in Northern England 1977-1986.

Crow et al $(199$ 票

\section{Aetiology}

Moving on to aetiology we are familiar with the man aetiological factors identified with chronic disease. W know that asthma is frequently triggered by exercise, col air or grass pollen and we recognise the link between smoking and coronary artery disease. But although we्लिafe aware of social factors in the prevalence or exacerbatio of disease we may not always appreciate its full significance. For example, in a study from Nottingtrau published in 1991 (2) in a 12 year follow up of pationts with brittle diabetes, it was found that nearly all instability was due to behaviourial or social factor another study from Newcastle looking at insư dependent diabetes in children in the North of England (\%) it was found that the incidence was related to materio deprivation (Fig 5). In a study of patients with Irritabe Bowel Syndrome in Andover and Southampton (4) heali beliefs and anxiety were associated with an increase in the number of consultations although these factors did $n \overrightarrow{\mathrm{gt}}$ seem to be part of the syndrome itself. The message clear. If we are to deal with some of the more difficit situations we have to be true family doctors and we have to do what we can to help address some of the background factors rather than simply lecturing patients 涺 they do not adhere to our advice.

\section{Social Impact}

Family doctors are aware of many of the implicatio of long term or recurrent conditions but we sometimgs forget the full extent of these. Here are some data from survey in Sheffield in 1991 reviewing patients who hat been admitted to hospital in the previous year (5). A thir of the adults had had to give up their job and over a thirf had some restriction on their activities. Nearly half the school age children had had some difficulties with spotit or physical activity and in many cases, the asthma hed affected holidays, household arrangements or finance. 
The authors go on to say: "This study belies the assertion that the effects of asthma can be fully controlled by the use of appropriate medication". There have been research studies which suggest that chronic disease may often be associated with feelings of stigma and pessimism $(6,7)$ In a survey in South Western Ontario(8) it emerged that negative feelings in patients with asthma were less to do with the specific disease and what other people thought and much more to do with the patients' personal attitudes and beliefs about themselves. The important point for us as general practitioners is that each person has their own individual beliefs and problems and they need to be elicited if we are to fully understand how patients may best be helped.

\section{Challenges}

So far I have tried to put long term and recurring health problems into context in terms of numbers and some of the interplay between disease and social factors. I want to turn now to some of the challenges that face us.

The first of these is making the diagnosis. Nine years ago in my James Mackenzie lecture for the Royal College of General Practitioners, I pointed out that there was evidence that diagnoses for conditions such as asthma, diabetes and hypertension were being missed $(9,10)$. I am sure we have advanced since then but regrettably there is still evidence that we could do better. In a survey from the Scottish heart health study published in 1990 (11) half the men with raised blood pressure had not been diagnosed and half of those in whom it had been detected were untreated. The figures for women were somewhat better but even so, $46 \%$ were undetected. Another survey from Leicester published last year showed significant variation among GPs when measuring blood pressure and diagnosing hypertension in the elderly (12). A recent study of children from Dundee (13) described the use of a specially trained asthma audit facilitator who examined the case records in 12 practices. By identifying key items associated with asthma such as mention of wheeze or periodic treatment of wheeze it appeared that there was a significant discrepancy between the number of children who probably had asthma and those in whom a formal diagnosis had been made. There is much evidence that depression goes unnoticed and it seems that there are factors both with the doctor and the patient which makes the detection less likely (14)

\section{Follow up and Recall}

So it seems that diagnosis continues to elude us some of the time. But although I believe we are getting better at it, diagnosing a condition does not always mean that it will be followed up correctly. One can hazard a guess why this might be so. Much medical education is based on diagnosing and treating. Long term supervision with the need to adhere to protocols is superficially less attractive and there is evidence to show it does not always happen.

In the paper from Scotland I mentioned previously from the Scottish heart health study (11), not only were half the population with raised blood pressure not being diagnosed but half of those in whom it had been detected were not 3 being treated and in half of those who were being treated, $\_$ the blood pressure was not controlled. Equally in the $?$ Leicester Study, there was variation between GPs as to what level of blood pressure in the elderly should be treated (12). Only last month a published survey from a $\underset{\vec{F}}{\vec{F}}$ health district in the north of England suggested that some $\overrightarrow{0}$ deaths from stroke or hypertensive disease could have $\frac{}{5}$ been avoided and that two of the factors were failure to $\overline{\bar{n}}$ follow up patients with raised blood pressure and to $\vec{\nabla}$ persuade others to stop smoking (15).

\section{Nurse Care}

Let us now look at some success stories in the follow up of patients with long term problems. The role of the nurse in primary health care has blossomed - some would say exploded - in the last decade. It seems that when it comes to issues of patient education and attention to detailed follow up, nurses have something very important to contribute.

A study from a practice in Norfolk has examined the N effects of a nurse run asthma clinic(16). The survey $\mathrm{N}$ involved over 100 children and adults with asthma and 을 demonstrated significant reductions in wheeze, nocturne attacks, overall trouble and interference with activitio $\frac{8}{8}$ such as walking uphill and climbing stairs. The number ơ GP home visits and days lost from work and school also fell. Another study has showed a reduction in doctor consultations, the use of oral steroids and the number of nebulisations following the introduction of a nurse clinis (17). In the first study, whilst nearly everyone had confidence in their doctor and felt that he or she had helped their asthma, only $32 \%$ felt they could talk to their doctor about their asthma. In my own practice we have seen the number of nebulisations and emergency

Paediatric Asthma Audit 1993

Parents of children with asthma surveyed -

$62 \%$ knew what a peak flow meter was for

95\% knew what to do in an acute attack

$77 \%$ knew which inhaler was a bronchodilator

Fig 6. Oxfordshire Audit Advisory Group.

consultations for asthma fall since one of our nurses has taken over the care of asthma. That patient education for asthma is crucial is not in doubt. A recent study from Nijmegen in the Netherlands, for example, estimated that rotahaler technique in obstructive airways disease was inadequate in over a quarter of patients and that nearly half were not taking the drugs in the frequency or dose $N$

they were supposed to be (18).
$A$ recent survey conducted in Oxfordshire, also on asthma is shown in Figure 6. 
What the asthma patients from Sheffield said they wanted in the way of help is shown in Figure 7

Requests for:

Information (causes, management, drugs etc)

Practical implications (holidays, housework etc)

Counselling

Practical help (nebulisers etc)

Fig 7. Survey of 50 Patients with Asthma previously admitted to Hospital in Sheffield.

Nocon and Booth (1991)

In my own practice in South Oxfordshire, where a third of the consultations in the building is done by nurses, we have found that the move to increasing the role of the nurse seems to have been beneficial. For example, they spend a considerable amount of time spread over three or four sessions of education with new diabetics and if we need to change someone over to insulin, all the details of technique are left to one of the nurses. Equally, follow up of hypertension is handled by the nurses virtually exclusively. We have recently started an arthritis clinic run by two nurses and one of the doctors: the trio were one of the three finalists for the 1993 Doctor of the Year Awards for arthritis care. For hypertension, diabetes and arthritis they work in pairs. Teamworking must be of a high order: nurses and doctors must use each other's expertise and patients need to be certain that everyone is following a common policy. It also has to be recognised, as Dr Norman Beale, a GP from Wiltshire has shown, that patients may wish to raise other matters when they attend nurse run chronic disease clinics (19). It is also important to try to ensure continuity of personal care by both doctor and nurse. We have carried out a preliminary survey into patients' attitudes to being supervised by nurses and intend to carry out a more detailed survey soon.

\section{Patients' beliefs and involvement}

That takes me now into the problem as seen by the patient. There is clear evidence from social psychologists and others that patients' health beliefs are integral to how they accept and make sense of advice from health professionals (20). Equally, there is evidence that patients are far more likely to follow advice if they are involved in some way in their management plan than if they are purely told what to do. For example, a patient who believes that inhaled steroids for asthma are dangerous and who does not have a chance to discuss those thoughts or be involved in the decision to put her daughter on to Becotide is not very likely to comply with the treatment. Equally, a patient who has not had the opportunity to talk through the cost benefit of commencing drugs for lowering his blood pressure, is quite likely to be unenthusiastic, especially if he has heard that some drugs may make him lethargic and impotent. Time spent, either by the nurse or the doctor, exploring ideas, concerns and expectations, and letting patients have a say in their ow management always pays off. Remember the diabetic and asthmatics whose poor control is related to socifi factors. Consider, too, how we would feel if we weres handed a prescription for hypotensive therapy if we weri asymptomatic and were unclear what the benefits woukd be or how the doctor had arrived at the decision.

\section{Principles of Care}

Let us now turn to how we can ensure that our ow care of long term problems is good. I suggest that the are certain principles of managing chronic disease properly which we can identify.

\section{Protocols}

First, we need to have agreed protocols and plans f $\overrightarrow{\phi 0}$ diagnosis and follow up. We have already seen that the continues to be questions about how good we are at thest activities and it would seek that protocols or guidelineß are the only answer.

Indeed, it is likely that in the future, if we cannof demonstrate how we make an important diagnosis with life long implications, we could find ourselves in som difficulties. Equally, inadequate supervision and contyg could also make things problematical for us.

The construction and adherence to protocols, howe are not without some difficulties. Doctors are of reluctant to accept some imposition of clinef랑 management, especially if they were not involved it its assembly. O'Dowd and Wilson said in 1991 "a degreg of freedom is necessary to allow for individual flair and innovation as doctors working in highly regulese environments and with strict protocols tend to perfor suboptimally"(21). So we have a problem since there clear evidence, not just from general practice, that patients are being denied appropriate treatment. What $\overrightarrow{w E}$ can do is to ensure that we have rigorous plans of protocols for diagnosis and follow up of long term problems, based on scientific data, whether produced house or taken off the shelf. We also need to accept tha there will be times that the application of such plans wi be inappropriate for particular patients.

So far most protocols or plans have been put togethe by professionals, usually doctors. There is another dangef here that the result may be too doctor centred and be mores concerned with readings and measurements than it is with. the quality of life. Much of our nurse arthritis clinig activity is to do with quality of life rather than just bloog tests and drugs. We need to experiment with patien involvement in the construction of protocols wher matters such as access, convenience, support and education feature as prominently as blood pressure, peaci flow and glucose readings.

\section{Teamwork}

Second, there is teamwork. I have argued that there are sound reasons for more use of nurses in long term care 
They are better than doctors at following protocols and they are good at explaining things and providing education. But if we are to develop this, teamwork needs to be of a high order with mutual respect and education and where our nursing colleagues are involved in the plans and protocols and not merely handed a set of instructions. There is also the hospital team to consider: we use our local diabetologist, rheumatologist and diabetic liaison nurses from time to time in our practice clinics where we can talk things through together.

\section{Records}

I have got nearly to the end of this lecture without mentioning records so I will make up for that now. If your practices are anything like mine, there are protocols and guidelines all over the place and I have great difficulty in locating them when needed. I have also seen protocols so complicated that it takes fifteen minutes simply to read them. I strongly believe that the solution to the retrieval problem is to have special flow sheets for each problem which both remind us what to do and make the surveillance of care so much easier.

\section{Audit}

It goes without saying that all long term disease care needs to be audited. It is essential that we are able to demonstrate how well we are doing and identify where we need to do better. Deficiencies in care are increasingly being splashed across the media and we must be able to answer our critics if our standards of care are challenged.

\section{Patient Involvement}

Finally, we need to involve patients in their care, not just in individual consultations but, as I have already suggested, in the development of practice plans and protocols.

These principles hold good for any long term health problem and I suggest their adoption would enhance our activities. They are all, in the Oxford GP Series book which Theo Schofield and I have edited and which, of course, you have all read(22).

\section{Implications for the Defence Medical Services}

So, finally what are the implications for the Defence Medical Services, in providing chronic disease care, particularly in the role as primary care doctors to families and dependants? It seems to me that they fall into three categories. First, the delivery of care itself, second, education for trainee GPs and third, audit and research.

\section{Delivery of care}

In the delivery of care, there are two separate aspects to consider the effectiveness of the care and who should do it.

For some long term problems, of which asthma is probably the best example, the challenges for Service doctors are no different to those for civilian GPs. You need to be able to identify the patients easily and you need to be sure you are aware of the latest evidence 2 regarding diagnosis and follow up. The increasing $\underset{\mathbb{\alpha}}{\vec{\alpha}}$ availability of computers makes the construction of $a$ 을 disease index and monitoring of prescribing much easier $\bigcirc$ than it used to be. I believe that you benefit fromo protocols and disease flow sheets as much as any other primary care doctor. You are also under similar pressures $\underset{\vec{\rho}}{\vec{F}}$ to audit your work.

What about those conditions you see less frequently흘 than your civilian counterparts, such as diabetes, $\frac{\bar{F}}{\vec{p}}$ hypertension, arthritis, thyroid disease, and so on? Here it $\mathbb{\Omega}$ seems to me that the use of protocols and flow sheets is even more relevant since we all find that it is more ${ }^{\infty}$ difficult to remember all the important aspects of a $\vec{\circ}$ disease if you deal with it only occasionally. You all have $\overrightarrow{\vec{H}}$ such patients, even if some of their care is being given by specialists. The small numbers should mean that the care can be audited without difficulty. One could be forgiven for not being confident about examining a diabetic fundus? but the enquiry about whether the eyes have been checked $\vec{f}$ annually by someone is not optional and needs to be recorded.

The other matter is to do with primary care team $N$ development in the Services. The challenge is trying to은 keep up with a rapidly changing scene outside. Th questions to be addressed seem to be the role and trainifg of the practice nurse together with her status argid relationship to her hospital counterpart. The responsibilities of today's primary care nurse are mapy and increasing and this has to be recognised.

\section{Vocational Training}

The Defence Medical Services have a well developed system of vocational training. One of the most frequento implied criticisms by outsiders, especially from some $\stackrel{\mathbb{Q}}{2}$ members of the Joint Committee, is that Service training $\overrightarrow{\overrightarrow{0}}$ practices do not provide the range of patients seen in $\overline{3}$ civilian practices.

I have answered this on numerous occasions in two ways. First, there are civilian practices with skewed $\bar{\xi}$ populations, such as those with high numbers of university students or in new city developments, and I have examples of both in my own region. Second, it is the $\frac{\vec{\sigma}}{\sigma}$ principles of chronic disease care that need to be learned by tomorrow's doctors and they can learn much about managing diabetes and arthritis from a patient with $\frac{0}{3}$. asthma. Give me a teacher with imagination and a skewed. list rather than a dull one with a so called normalo population any day.

So what those Service doctors who are approved as GP을 trainers need to do is to ensure that the principles of long term care are grasped and naturally that audit of that care is being undertaken on a regular basis.

\section{Research}

Third, research. There is still much we do not know N about the social factors and implications for long term 
health problems. One of the earliest papers I recall reading on the subject was written by an RAF Medical Officer in Germany in the late sixties looking at the relationship between housing and demand for primary medical care. The Service practices are in an ideal position to investigate the effect of mobility, marital separation and other matters on the conditions such as asthma and depression. I hope some of you will rise to the challenge.

\section{Conclusion}

In tonight's lecture I have argued that we have much to do to build on work already accomplished to provide the best possible primary care for our patients with long term health problems. Much of that work is to do with organisation and teamwork. I have also suggested that although some of these problems are less prevalent in the Services, they are not non existent and furthermore the practices approved for training have to use their opportunities well to ensure that trainee GPs are appropriately educated.

Over the years I have seen great changes in Service general practice and I and my colleagues are grateful for all you do in your primary role in the defence of this country. I am well aware that things are not always easy for you and that frustrations are common but my time spent in your company is always enjoyable and I recognise that you have achieved much. It may well be that David Bruce, were he alive today, and recognising his early career in general practice, would have devoted his great talents to Army general practice, which has a great future ahead of it.

\section{REFERENCES}

1. Knottnerus J A, Metsemakers J, Hoppener P, et al. Chronic illness in the community and the concept of social prevalence. Fam Pract 1992; 9: 15 - 21.

2. Tattersall R, Gregory R, Selby C, et al. Course of brittle diabetes: 12 year follow up. Br Med J 1991; 302: 1240 - 1243.

3. Crew Y J, Alberti Kamm, Parkin J M. Insulin dependent diabetes in childhood and material deprivation in Northern England. 1977-86. Br Med J 1991; 303: 158-160.

4. Kettell J, Jones R, Lydeard S. Reasons for Consultations in Irritable Bowel Syndrome: Symptoms and patient characteristics. Br J Gen Pract 1992, 42: 459-461.

5. Nocon A, Booth T. The Social Impact of Asthma. Fam Pract 1991; 8: 37-41.

6. SibBald B, White P, Pharaoh C. et al. Relationship between psychosocial factors and asthma morbidity. Fam Pract 1988; 5: 12-17.
7. McClewan V E, Garret J E. Asthma and th employment experience. $N Z$ Med $J$ 1990; 103: 399 401.

8. SnAdden D, Brown J.B. Asthma and Stigmå Fam Pract 1991; 8: 329-335.

9. Speight A N P, LeE D A, Hey E N. Underdiagnos and undertreatment of asthma in childhood. $\mathrm{Br} \mathrm{Med}$ 1983; 1253-1255.

10. Schofield T P C. Hypertension. Chapter Continuing Care. Editors Hasler J C and Schofie T P C. Oxford University Press, 1990. GP Series $1 \frac{9}{2}$ 2nd Ed.

11. Smith W C S., Lee A J, Crombie I K et al. Contrô? of blood pressure in Scotland: the rule of halves BrMed J 1990; 300: 981-983.

12. Fotherby M D, HaRper G D, Potter J F. Genera Practitioners' management of hypertension in eldery patients. Br Med J 1992; 305: 750-752.

13. Neville R G, Bryce F P, Robertson F M, et $d \stackrel{P}{\text { Th }}$. Diagnosis and treatment of asthma in childrem usefulness of a review of medical records Br J Gen Pract 1992; 42: 501-503.

14. SKuSE D, WILliams P. Screening for psychiatrio disorder in general practice. Psychol Med 1984; 1 \& 365-377.

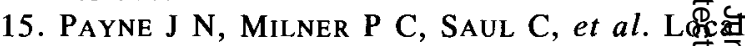
Confidential Enquiry into avoidable factors in degth from stroke and hypertension disease. $\mathrm{Br}$ Med J 1 院 307: 1027-1030.

16. Charlton I, Charlton G, Broomfield J, et al atid evaluation of a nurse-run asthma clinic in generg practice using an attitudes and morbi画控 questionnaire. Fam Pract 1992; 9: 154-160.

17. Charlton I H, Charlton G F A, Broomfield A, al. Audit of the effect of a nurse run asthma clinic workload and patient morbidity in a general practice Br J Gen Pract 1991, 41: 227-231.

18. Dompeling E, Van Grunsven P M, Van Shaycog $\mathrm{C} \mathrm{P}$, et al. Treatment with inhaled steroids in asthmat and chronic bronchitis: long term compliance an inhaler technique. Fam Pract 1992; 9: 161-166.

19. Beale N, Searle M, Woodman J. Use made bæ patients of chronic disease surveillance consultation in general practice. Br J Gen Pract 1992; 42: 51-53.

20. Doctor-Patient Communication. Editors Pendleto D A and Hasler J C. Academic Press, London, 1983.

21. Dowd T C, WiLson A D. Set menus and clinica freedom. Br Med J 1991; 303: 450-452.

22. Continuing Care: the management of chronic diseas 2nd Edition. Editors Hasler J C and Schofield T P o Oxford University Press, 1990. GP Series 19. 